\title{
EVALUASI PENGGUNAAN ANTIBIOTIK DENGAN METODE ATC/DDD DAN DU 90\% DI PUSKESMAS KEBUN HANDIL KOTA JAMBI PERIODE 2018 DAN 2019
}

\section{EVALUATION OF ANTIBIOTIC USE WITH ATC / DDD AND DU 90\% METHOD IN HANDIL GARDEN HEALTH CENTER JAMBI CITY PERIOD 2018 AND 2019}

\author{
Yuni Andriani* ${ }^{1}$, Indri Meirista ${ }^{2}$, Yego Aprio ${ }^{3}$ \\ Yuni Andriani, Jl. Tarmizi Kadir Pakuan Baru Jambi City and 36132, Indonesia \\ Indri Meirista, J1. Tarmizi Kadir Pakuan Baru Jambi City and 36132, Indonesia \\ Yego Aprio, Jl.Tarmizi Kadir Pakuan Baru, Jambi City and 36132, Indonesia \\ *Koresponding Penulis: ${ }^{1}$ yuni23_fmasi@yahoo.com; ${ }^{2}$ indri.meirista@stikes-hi.ac.id ; ${ }^{3}$ yegoaprio23@gmail.com
}

\begin{abstract}
Abstrak
Metode ATC / DDD merupakan metode klasifikasi dan pengukuran penggunaan obat yang saat ini telah menjadi salah satu pusat perhatian dalam pengembangan penelitian penggunaan obat. Penggunaan metode ATC/DDD dapat diintegrasikan dengan DU 90\% (Drug Untilization) untuk mengidentifikasi segmen penggunaan terbanyak dalam studi penggunaan obat di suatu populasi. Penelitian ini bertujuan untuk mengetahui kuantitas penggunaan antibiotik rawat jalan di Puskesmas Kebun Handil Kota Jambi berdasarkan metode ATC/DDD dan DU90\% periode 2018 dan 2019Penelitian ini merupakan penelitian kuantitatif dengan pengambilan data secara retrospektif di Puskesmas Kebun Handil Kota Jambi periode Januari 2018 sampai Desember 2019. Data yang digunakan adalah data rekam medik pasien rawat jalan yang mendapat terapi antibiotik sesuai dengan kriteria inklusi. Hasil penelitian ini menunjukkan bahwa antibiotik yang paling banyak digunakan pada Puskesmas Kebun Handil Kota Jambi periode 2018 dan 2019 adalah amoxicillin.
\end{abstract}

Kata kunci : ISPA, Antibiotik, Puskesmas Kebun Handil Kota Jambi

\section{Abstract}

The ATC / DDD method is a method of classification and measurement of drug use which has now become one of the centers of attention in the development of drug use research. The use of ATC / DDD methods can be integrated with DU 90\% (Drug Untilization) to identify the most usage segments in studies of drug use in a population. This study aims to determine the quantity of outpatient antibiotic use at the Kebun Handil Health Center in Jambi City based on the ATC / DDD and DU90\% methods for the 2018 and 2019 periods. This research is a quantitative study with retrospective data collection at the Kebun Handil Health Center in Jambi City in the period January 2018 to December 2019. The data used are medical records of outpatients receiving antibiotic therapy according to inclusion criteria. The results of this study indicate that the most widely used antibiotic at the Jambi Handil Health Center in the 2018 and 2019 periods is amoxicillin.

Keywords: ISPA, Antibiotics, Kebun Handil Health Center, Jambi City 
Journal of Healthcare Technology and Medicine Vol. 6 No. 2 Oktober 2020

Universitas Ubudiyah Indonesia

e-ISSN : 2615-109X

\section{PENDAHULUAN}

Metode ATC / DDD merupakan metode klasifikasi dan pengukuran penggunaan obat yang saat ini telah menjadi salah satu pusat perhatian dalam pengembangan penelitian penggunaan obat (Mahmudah dkk., 2016). Penggunaan metode ATC/DDD dapat diintegrasikan dengan DU 90\% (Drug Untilization) untuk mengidentifikasi segmen penggunaan terbanyak dalam studi penggunaan obat di suatu populasi (Hasrianna et al., 2015). Badan Kesehatan Dunia (WHO), sejak 1996 menganjurkan penggunaan ATC (Anatomical Theraupetic Chemical) bersamaan dengan unit DDD (Defined daily dose) sebagai standar untuk memperoleh data yang baku (WHO, 2018).

Akademi Sains Nasional mengungkapkan data konsumsi antibiotik di 76 negara meningkat 65\% pada tahun 2015 dibandingkan tahun 2000. Konsumsi antibiotik yang meningkat didominasi oleh negara-negara berpenghasilan rendah dan menengah. Dari 76 negara yang diteliti, jumlah konsumsi antibiotik pasien rawat jalan meningkat dari 21,2 miliar DDD pada tahun 2000 menjadi 34,8 miliar DDD pada tahun 2015 (Klein et al., 2018). Penggunaan antibiotik perlu dimonitoring karena diketahui bahwa penggunaan antibiotik yang berlebihan dapat meningkatkan terjadinya resistensi, hal ini pun menjadi fokus secara nasional maupun global (Pani et al., 2015).

Penelitian yang menggunakan metode ATC/DDD untuk pasien rawat jalan di Indonesia masih sangat sedikit beberapa diantaranya adalah di RSUD Abepura Jayapura periode April 2013-Maret 2014 menunjukan pemakaian antibiotik tertinggi yaitu Cotrimoxazole (Hasrianna et al., 2015). Di Puskesmas Kabupaten Gorontalo Utara antibiotik yang masuk segmen DU 90\% yang paling banyak digunakan adalah Amoxicilin $500 \mathrm{mg}$ sebanyak (2723 DDD/1000 pasien/hari) (Pani et al., 2015). Di Bagian Bedah Digesif Rumah Sakit Bandung menunjukan bahwa secara kuantitas penggunaan antibiotik yang paling banyak adalah Ceftriaxone sebesar (8,77) DDD/100 hari rawat (Mahmudah dkk., 2016). Hasil penelitian yang dilakukan di Puskesmas Karawang menunjukan bahwa dari 81 catatan medis didapatkan 6 jenis antibiotik yang digunakan dengan jumlah penggunaan $(144,5)$ DDD/100 hari rawat. Sedangkan antibiotik yang masuk segmen DU90\% adalah Amoxicilin $(65,75)$ DDD/100 rawat dan Cefoperazon $(45,89)$ DDD/100 rawat (Sholih dkk., 2015).

Meningkatnya penggunaan antibiotik serta masih sangat sedikitnya penelitian di beberapa Puskesmas di Indonesia dan beberapa Puskesmas di Kota Jambi membuat peneliti tertarik untuk melakukan penelitian penggunaan antibiotik dengan metode ATC/DDD dan DU 90\% di Puskesmas Kebun Handil Kota Jambi periode 2018 dan 2019 untuk mengetahui kuantitas penggunaan antibiotik. 
Journal of Healthcare Technology and Medicine Vol. 6 No. 2 Oktober 2020

Universitas Ubudiyah Indonesia

e-ISSN : 2615-109X

\section{METODE PENELITIAN}

Penelitian ini merupakan penelitian kuantitatif dengan pengambilan data secara retrospektif di Puskesmas Kebun Handil Kota Jambi periode Januari 2018 sampai Desember 2019. Data yang digunakan adalah data rekam medik pasien rawat jalan yang mendapat terapi antibiotik sesuai dengan kriteria inklusi.

Kriteria inklusi, pasien yang menggunakan antibiotik pada periode Januari 2018 sampai Desember 2019, antibiotik yang digunakan memiliki kode ATC J01, dan Rekam medik, resep dan buku register yang lengkap dan dapat terbaca dengan jelas, meliputi usia pasien, nama antibiotik, bentuk sediaan, kekuatan sediaan dan total tablet yang digunakan. Kriteria ekslusi Pasien anak-anak $<17$ tahun.

\section{HASIL DAN PEMBAHASAN}

Berdasarkan penelitian yang telah dilakukan di Puskesmas Kebun Handil Kota Jambi periode 2018 dan 2019 didapatkan hasil penelitian berupa jenis kelamin, usia, diagnosa penyakit, jenis antibiotik yang digunakan, nilai DDD/1000 pasien dan segmen DU 90\%

\section{ANALISA KUANTITATIF}

A. Karakteristik Pasien Berdasarkan Jenis Kelamin

\begin{tabular}{|c|c|c|}
\hline \multirow{2}{*}{ Jenis Kelamin } & \multicolumn{2}{|c|}{ Puskesmas Kebun Handil Kota Jambi } \\
\cline { 2 - 3 } & $\mathbf{2 0 1 8}$ & $\mathbf{2 0 1 9}$ \\
\hline Laki-laki & 85 & 85 \\
\hline Perempuan & 144 & 148 \\
\hline Total & 229 & 233 \\
\hline
\end{tabular}

B. Karakteristik Pasien Berdasarkan Usia

\begin{tabular}{|c|c|c|}
\hline \multirow{2}{*}{ Usia } & \multicolumn{2}{|c|}{ Puskesmas Kebun Handil Kota Jambi } \\
\cline { 2 - 3 } & $\mathbf{2 0 1 8}$ & $\mathbf{2 0 1 9}$ \\
\hline $18-25$ & 34 & 33 \\
\hline $26-35$ & 42 & 42 \\
\hline $36-45$ & 42 & 43 \\
\hline $46-55$ & 24 & 34 \\
\hline $56-65$ & 40 & 33 \\
\hline$>65$ & 47 & 48 \\
\hline Total & 229 & 233 \\
\hline
\end{tabular}


Journal of Healthcare Technology and Medicine Vol. 6 No. 2 Oktober 2020 Universitas Ubudiyah Indonesia e-ISSN : 2615-109X

\section{Karakteristik Pasien Berdasarkan Diagnosa Penyakit}

\begin{tabular}{|c|c|c|}
\hline \multirow{2}{*}{ Diagnosa Penyakit } & \multicolumn{2}{|c|}{ Puskesmas Kebun Handil Kota Jambi } \\
\cline { 2 - 3 } & $\mathbf{2 0 1 8}$ & $\mathbf{2 0 1 9}$ \\
\hline Ispa & 137 & 30 \\
\hline Febris & 28 & 21 \\
\hline ISK & 13 & 21 \\
\hline Dermatitis & 13 & 12 \\
\hline Diare & 12 & 8 \\
\hline Myalgia & 9 & 14 \\
\hline Abses & 2 & 8 \\
\hline Nekrosis Pulpa & 3 & 0 \\
\hline Konjungtivitas & 5 & 6 \\
\hline Otitis & 2 & 4 \\
\hline Tonsilitis & 0 & 73 \\
\hline Varicella & 5 & \\
\hline Total & & \\
\hline & & \\
\hline
\end{tabular}

\section{Jenis Penggunaan Antibiotik}

\begin{tabular}{|c|c|c|}
\hline \multirow{2}{*}{ Jenis Antibiotik } & \multicolumn{2}{|c|}{ Puskesmas Kebun Handil Kota Jambi } \\
\cline { 2 - 3 } & $\mathbf{2 0 1 8}$ & $\mathbf{2 0 1 9}$ \\
\hline Amoxicillin & 158 & 128 \\
\hline Ciprofloxacin & 48 & 41 \\
\hline Cefadroxil & 14 & 49 \\
\hline Erythromycin & 9 & 9 \\
\hline Chloramphenicol & 0 & 6 \\
\hline Total & 229 & 233 \\
\hline
\end{tabular}


Journal of Healthcare Technology and Medicine Vol. 6 No. 2 Oktober 2020

Universitas Ubudiyah Indonesia

e-ISSN : 2615-109X

\begin{tabular}{|c|c|c|c|c|}
\hline Antibiotik & Kode ATC & DDD/1000 & $\%$ & $\%$ Kumulatif \\
\hline Amoxicillin & J01CA04 & 45,504 & $62,499 \% *$ & $62,499 \%$ \\
\hline Ciprofloxacin & J01MA02 & 20,391 & $28,007 \% *$ & $90,506 \%$ \\
\hline Cefadroxil & J01DB05 & 3,024 & $4,153 \%$ & $94,660 \%$ \\
\hline Erythromycin & J01FA01 & 3,888 & $5,340 \%$ & $100,00 \%$ \\
\hline \multicolumn{2}{|r|}{ Total } & 72,807 & $100,00 \%$ & \\
\hline
\end{tabular}

\begin{tabular}{|c|c|c|c|c|}
\hline Antibiotik & Kode ATC & DDD/1000 & $\%$ & $\%$ Kumulatif \\
\hline Amoxicillin & J01CA04 & 35,236 & $53,557 \% *$ & $53,557 \%$ \\
\hline Ciprofloxacin & J01MA02 & 16,682 & $25,356 \% *$ & $78,912 \%$ \\
\hline Cefadroxil & J01DB05 & 9,745 & $14,812 \% *$ & $93,764 \%$ \\
\hline Erythromycin & J01FA01 & 3,716 & $5,648 \%$ & $99,37 \%$ \\
\hline Chlorampenicol & J01BA01 & 0,413 & $0,63 \%$ & $100 \%$ \\
\hline Total & 65,792 & $100,00 \%$ & \\
\hline
\end{tabular}

Keterangan : $*=90 \%$

\section{KESIMPULAN}

Berdasarkan penelitian yang telah dilakukan, antibiotik yang paling banyak digunakan pada Puskesmas Kebun Handil Kota Jambi periode 2018 dan 2019 adalah amoxicillin.

Diketahui nilai DDD antibiotik amoxicillin pada periode 2018 adalah 45,504 DDD/1000 KPRJ dan 35,236 DDD/1000 KPRJ pada periode 2019, antibiotik yang masuk segmen DU 90\% di Puskesmas Kebun Handil Kota Jambi periode 2018 adalah amoxicillin dan ciprofloxacin sedangkan pada periode 2019 adalah amoxicillin, ciprofloxacin dan cefadroxil.

\section{SARAN}

Perlu dilakukan studi kualitatif mengenai rasionalitas penggunaan antibiotik, khususnya antibiotik yang masuk segmen DU 90\% di Puskesmas Kebun Handil Kota Jambi periode 2018 dan 2019 sebagai upaya pengendalian resistensi antibiotik.

\section{DAFTAR PUSTAKA}

Alfian, S. D., Tarigan, E. S., Puspitasari, I. M., \& Abdulah, R. (2012). Profil Penggunaan Antituberkulosis di Apotek di Kota Bandung Periode 2008 - 2010. Jurnal Farmasi Klinik Indonesia, 1(December), 147-153.

Astuti, D., \& Arfania, M. (2018). Analisis Penggunaan Antibiotika Dengan Metoda ATC/DDD di Rumah Sakit Swasta Kab Karawang. Pharma Xplore : Jurnal Sains Dan Ilmu Farmasi, 3(2), 194-202.

Cunha, Burke A, MD, MACP. (2014). Esensial Antibiotik (Edisi 7).Jakarta : EGC

Hasrianna, Annisa, N., Milanda, T., Pradipta, I. S., \& Abdulah, R. (2015). Monitoring Use of Antibiotics with ATC/DDD and DU90\% Method in Abepura Hospital Jayapura, 
Journal of Healthcare Technology and Medicine Vol. 6 No. 2 Oktober 2020

Universitas Ubudiyah Indonesia

e-ISSN : 2615-109X

Indonesia. Indonesian Journal of Clinical Pharmacy, 4(3), 218-225.

Katzung, B. G., Masters, susan B., \& Anthony J. Trefor. (2012). Basic \& Clinical Pharmacology Edisi 12.

Kemenkes (2013). Peraturan Menteri Kesehatan Republik Indonesia Nomor 2406/Menkes/per/XII/2013 tentang Pedoman Umum Penggunaan Antibiotik.

Kementrian kesehatan. (2011). Peraturan menteri kesehatan Republik Indonesia tentang pedoman pelayanan kefarmasian untuk terapi antibiotik.

Kementrian kesehatan. (2017). Peraturan menteri kesehatan Republik Indonesia nomor 2406/Menkes/per/XII/2017 tentang pedoman umum penggunaan antibiotik.

Klein, E. Y., Boeckel, T. P. Van, Martinez, E. M., Pant, S., Gandra, S., \& Levin, S. A. (2018). Global increase and Geographic Convergence in Antibiotic Consumption Between 2000 and 2015. PNAS Lates Article, 1-8.

Linehan, E, and D C Fitzgerald. 2015. "Ageing and the Immune Syste: Focus on Macrophages. European Journal of Microbiology and Immunology 5(1): 14-24.

Mahmudah, F., Sumiwi, S. A., \& Hartini, S. (2016). Study of the Use of Antibiotics with ATC/DDD System and DU 90\% in Digestive Surgery in Hospital in Bandung. Indonesian Journal of Clinical Pharmacy, 5(4), 293-298.

Muslim, Z. (2018). Antibiotic Prescription to Pediatric in Hosptal Bengkulu, INDONESIA : ATC / DDD INDEX. International Journal Of Pharmacy And Pharmaeutical Sciences, 10(5), 10-13.

Marlina, M., Saputra, W., Mulyadi, B.,Hayati, B., \& Jaroji, J. (2017). Aplikasi sistem pakar diagnosis penyakit ispa berbasis speech recognition menggunakan metode naive bayes classifier. Digital Zone: Jurnal Teknologi Informasi dan Komunikasi, 8(1), 58-70.

Naik, H. G., Khanwelkar, C. C., Kolur, A., Desai, R., \& Gidamudi, S. (2018). Drug Utilization Study on Antibiotics Use in the Upper Respiratory Tract Infection. Antibotic Prescription to Pediatric in Hospital Bengkulu, Indonesia: ATC/DDD INDEX, 10(5), 31-34.

Pangestika, N. W. (2017). Hubungan Antara Tingkat Pendidikan dan Pengetahuan Terhadap Rasionalitas Pengunaan Antibiotik pada Kader PKK di 17 Kecamatan Wilayah Kabupaten Banyumas. Fakultas Farmasi Universitas Muhammadiyah Purwokerto, $4-10$.

Pani, S., Barliana, M. I., Halimah, E., Pradipta, I. S., \& Annisa, N. (2015). Monitoring Penggunaan Antibiotik dengan Metode ATC / DDD dan DU 90 \%: Studi Observasional di Seluruh Puskesmas Kabupaten Gorontalo Utara Monitoring the 
Journal of Healthcare Technology and Medicine Vol. 6 No. 2 Oktober 2020

Universitas Ubudiyah Indonesia

e-ISSN : 2615-109X

Use of Antibiotics by the ATC / DDD Method and DU $90 \%$ : Observational Studies in Community Health Servi. Jurnal Farmasi Klinik, 4(4), 275-280.

Pradipta, I. S., Febrina, E., Ridwan, M. H., \& Ratnawati, R. (2012). Identifikasi Pola Penggunaan Antibiotik sebagai Upaya Pengendalian Resistensi Farmasi Klinik, 1, $16-24$.

Patel, S., Shah, A., \& Shah, R. B. (2016). Evaluation of Drug Utilization Pattern of Antimicrobials Using ATC / DDD System in Intensive Care Unit of a Tertiary-Care Teaching Hospital. International Journal of Medical Science and Public Health, $5(01), 2-6$.

Radji, Maksum. (2014). Mekanisme aksi molekuler antibiotik dan kemoterapi.Jakarta: EGC.

Sholih Mally G, Ahmad Muhtadi, Siti Saidah. (2015). Rasionalitas Penggunaan Antibiotik di Salah Satu Rumah Sakit Umum di Bandung Tahun 2010.Jurnal Farmasi Klinik, 4,01: 63-70.

Utami, eka rahayu. (2011). Antibiotika, Resistensi, Dan Rasionalitas Terapi. Jurnal Fakultas Saintek, Universitas Islam Negeri Maulana Malik Ibrahim. Malang. 1(4): 191-98.

Vascarya, C., Susanti, R., \& Nurmainah. (2016). Evaluasi Penggunaan Antibiotika Berdasarkan Metode Prescribed Daily Dose ( PDD ) Pada Anak Di Rawat Inap Puskesmas Siantan Hilir Pontianak Periode Juli - Desember 2016. Universitas Tanjungpura.

World health organization. (2018). Collaborating centere for drug statistic methodology ATC and DDD.

World health organization. (2019). Guidelines for ATC clasification and DDD asigment.

Yuana D.A. (2014). Gambaran Penggunaan Antibiotik dengan Resep dan Tanpa Resep Dokter Beberapa Apotek di Area Jember Kota.

Yanuar, W., Puspitasari, I., \& Nuryastuti, T. (2016). Outcome pada Pasien Anak Dengan Meningitis Bakterial di Evaluation of Definitive Antibiotik Suitability for Clinical Outcomein. Jurnal Manajemen Dan Pelayanan Farmasi, 6(3), 187-204. 
Journal of Healthcare Technology and Medicine Vol. 6 No. 2 Oktober 2020 Universitas Ubudiyah Indonesia e-ISSN : 2615-109X 